\title{
Two-Stage Dilute-Acid and Organic-Solvent Lignocellulosic Pretreatment for Enhanced Bioprocessing
}

\author{
G. Brodeur ${ }^{1}$, J. Telotte ${ }^{1}$, J. J. Stickel ${ }^{2}$ and S. Ramakrishnan ${ }^{1}$ * \\ ${ }^{1}$ Department of Chemical and Biomedical Engineering \\ FAMU-FSU College of Engineering, 2525 Pottsdamer Street \\ Tallahassee, Florida 32310 \\ ${ }^{2}$ National Renewable Energy Laboratory, National Bioenergy Center \\ Golden, Colorado 80401
}

*Corresponding Author

S. Ramakrishnan

Phone: 850-410-6159

Fax: 850-410-6150

sramakrishnan@fsu.edu 


\begin{abstract}
A two stage pretreatment approach for biomass is developed in the current work in which dilute acid (DA) pretreatment is followed by a solvent based pretreatment (N-methyl Morpholine $\mathrm{N}$ Oxide - NMMO). When the combined pretreatment (DAWNT) is applied to sugarcane bagasse and corn stover, the rates of hydrolysis and overall yields (> 90\%) are seen to dramatically improve and under certain conditions 48 hours can be taken off the time of hydrolysis with the additional NMMO step to reach similar conversions. DAWNT shows a 2-fold increase in characteristic rates and also fractionates different components of biomass - DA treatment removes the hemicellulose while the remaining cellulose is broken down by enzymatic hydrolysis after NMMO treatment to simple sugars. The remaining residual solid is high purity lignin. Future work will focus on developing a full scale economic analysis of DAWNT for use in biomass fractionation.
\end{abstract}

Keywords: enzymatic hydrolysis; biomass to biofuels, cellulose, multi stage treatment 


\section{Introduction}

Lignocellulosic biomass represents a promising feedstock for fermentative biofuel production (Geddes et al., 2010; Geddes et al., 2015). In addition, due to the number of components present in the biomass, it is also a valuable source for production of other value added chemicals and products in addition to liquid transportation fuels (Sawisit et al., 2015; Wang et al., 2013). However, naturally occurring biomass is highly recalcitrant, and pretreatment strategies need to be developed which breaks up the crystalline structure and to fractionate the different components. The overall digestibility of the substrates by enzymes following pretreatment is dependent on a number of factors such as accessibility, degree of polymerization of cellulose, crystallinity, particle size, porosity, and biomass content, to name a few, and the pretreatment strategy needs to take into account these factors to improve the subsequent processing steps by cellulases (Bansal et al., 2012; Brodeur et al., 2011). Typically a single pretreatment strategy is able to alter only some of these factors resulting in material that is still partially inaccessible for enzymatic hydrolysis.

Dilute-acid treatment in combination with steam explosion has been successfully implemented at the pilot-plant scale for a number of substrates (Geddes et al., 2010; Schell et al., 2003). The major advantages of dilute-acid treatment is the capability to hydrolyze the majority of the hemicellulosic fraction while also disrupting the biomass structure through alterations of the lignin structure (Kumar et al., 2009). Accordingly, the cellulosic fraction will have higher accessibility owing to the partial removal of the hemicellulose and lignin sheathing. There are an array of conditions that have been used for dilute-acid treatments that include the use of a variety of feedstocks, altering acids and acid concentrations, temperatures, retention time, and addition of explosive decompression (Geddes et al., 2010; Jackson de Moraes Rocha et al., 2011; Jensen 
et al., 2010; Li et al., 2010; Schell et al., 2003; Silverstein et al., 2007; Tian et al., 2011; Um et al., 2003; Wyman et al., 2011; Yoon et al., 2011). However subsequent enzymatic hydrolysis reveals that $\sim 15 \%$ of the cellulosic fraction is still inaccessible in a majority of the studies.

Solvent-based pretreatments have recently been used for pretreatment primarily driven by the ability to carry out the treatment at lower temperatures $\left(90-130{ }^{\circ} \mathrm{C}\right)$ and by the ability to tune the chemistry of the solvent (ionic liquids) to dissolve/affect different components of the biomass (Brodeur et al., 2011; Dadi et al., 2007; Dadi et al., 2006). A solvent which has been commercially used to produce Tencel ${ }^{\circledR}$ fibers and for pretreatment is $\mathrm{N}$-methyl morpholine Noxide (NMMO). NMMO is an excellent solvent for dissolving cellulose - it disrupts the hydrogen bond network that keeps the cellulose polymers together and swells the substrate, thus making it more amenable for subsequent enzymatic hydrolysis (Collier et al., 2003; Petrovan et al., 2001; Ramakrishnan et al., 2010). However the presence of other lignocellulosic materials in the biomass does influence the action of NMMO (and other solvents) resulting in lower conversions. Just like in the dilute acid treatment, there is still a percentage of biomass that is not accessible ( 20\%) (Jeihanipour et al., 2010; Kuo \& Lee, 2009; Lennartsson et al., 2011; Poornejad et al., 2011; Shafiei et al., 2010; Vahid et al., 2011; Wang et al., 2011).

In this work the effects of dilute-acid and NMMO treatments are combined to yield a two-stage process (dilute acid followed by NMMO treatment - DAWNT) that leads to near complete conversion. The aim is to show that DAWNT process not only results in reduced times to achieve a given conversion but also enhances hydrolysis rates and results in a near complete fractionation of the lignocellulosic components. A schematic of DAWNT is given in Figure 1.

\section{Materials and Methods}


Untreated corn stover (CS) and CS treated by dilute sulfuric acid (DSA) steam explosion was generously provided by the National Renewable Energy Laboratory (Golden, CO - NREL). The treatments were run at pilot plant scale according to Schell et al., 2003 (Schell et al., 2003). The specific conditions used for the material in this work consisted of 1 minute retention times at $190^{\circ} \mathrm{C}$ and an acid concentration of $0.5 \% \mathrm{w} / \mathrm{w} \mathrm{H}_{2} \mathrm{SO}_{4}$. The corn stover had a moisture content of $\sim 27 \%$. This material was washed with deionized water four times before being used for enzymatic hydrolysis. Once washed the samples were sealed and stored in a refrigerator. The samples were used within a period of 2 weeks.

Untreated sugarcane bagasse (SB) and bagasse treated by dilute phosphoric acid (DPA) steam explosion was generously provided by Dr. Shanmugam at the University of Florida working with the Florida Center for Renewable Chemicals and Fuels (Perry, FL). The treatments were run at pilot plant scale according to Geddes et al., 2010 (Geddes et al., 2010). The specific conditions used for the material in this work consisted of a 5 minute retention time at $190^{\circ} \mathrm{C}$ and an acid concentration of $0.5 \% \mathrm{w} / \mathrm{w}$ phosphoric acid. Sugarcane bagasse obtained from the pilot plant at UF had a moisture content of $48 \%$. This material was washed with deionized water four times before being used for enzymatic hydrolysis. Once washed the samples were sealed and stored in a refrigerator. The samples were used within a period of 2 weeks.

$\mathrm{N}$-methyl morpholine $\mathrm{N}$-oxide (NMMO) (50\% w/w aqueous solution) mixture was obtained from Sigma Aldrich Co. This solution was dehydrated to the monohydrate point ( 13.3 wt $\%$ water) for use in pretreatment. This was done by placing an amount of the aqueous solution in a rotovap under vacuum at $86^{\circ} \mathrm{C}$ until the proper mass of water had been boiled off. NMMO treatment was done by adding three grams of biomass (dry weight of corn stover and sugarcane 
bagasse) to $97 \mathrm{~g}$ of NMMO monohydrate $\left(3 \% \mathrm{w} / \mathrm{w}\right.$ solids loading) at $100^{\circ} \mathrm{C}$. After a set treatment time period of three hours the solution was slowly poured into a beaker of water (400 $\mathrm{mL}$ ), where the treated material would precipitate out of solution. The precipitated mixture was vigorously agitated by shaking followed by centrifugation at 7000 RPM for $10 \mathrm{~min}$. Subsequent washing and repeated centrifugation followed until a clear supernatant (4-5 washes) was observed in order to wash away the remaining NMMO. To study the solid and NMMO recovery, pretreatment experiments were conducted in which $3 \mathrm{~g}$ of biomass was treated with 97 $\mathrm{g}$ of NMMO monohydrate at $100 \mathrm{C}$ for three hours. After pretreatment, $400 \mathrm{ml}$ of water was added to the mixture to regenerate the cellulose and the mixture was filtered to recover the solids (98\% solids were recovered $-2.94 \mathrm{~g}$ ). This dilute recycle stream had activated charcoal added $(0.5 \mathrm{~g})$ to adsorb any $\mathrm{N}$-methyl morpholine formed and was then filtered. In the process of filtration, the average recovery of solvent was $97.4 \% \mathrm{NMMO}$ monohydrate $(94.47 \mathrm{~g})$. The water in the NMMO was boiled off using vacuum distillation (at low temperatures) to obtain the monohydrate that was then used to pretreat fresh biomass.

The commercial enzyme used in this work was the cellulase mixture Cellic CTec2 that was generously provided by Novozymes North America. This cellulase mixture was measured to have a protein concentration of $93.8 \mathrm{mg}_{\text {Protein }} / \mathrm{mL} \mathrm{CTec} 2$ solution according to Bradford method (Bradford, 1976) and an activity of $119.6 \mathrm{FPU} / \mathrm{mL}$ (Ghose, 1987). The mixtures were kept sealed at $4^{\circ} \mathrm{C}$ until needed for experimentation. All enzymatic hydrolysis experiments (of different substrates) were carried out at a solids loadings of $10 \mathrm{mg}$ biomass/g total solution, $\mathrm{pH}$ of 4.9 and at $50^{\circ} \mathrm{C}$. The enzyme loading was kept constant at $10 \mathrm{mg}_{\text {Protein }} / \mathrm{g}_{\mathrm{Glucan}}$ (corresponding to $7.5 \mathrm{FPU} / \mathrm{g}_{\text {Glucan }}$ ) for all experiments. Before all hydrolysis reactions, a dry weight of a small 
amount of wet sample $(\sim 2 \mathrm{~g})$ was determined which was then used to calculate the reaction concentration of $10 \mathrm{mg} / \mathrm{g}$.

The enzymatic hydrolysis results given throughout this work are presented in terms of glucan conversion as a function of time. In order to determine the glucan conversion to glucose Equation 1 is used. The factor of 0.90 comes from the difference in molar masses of glucan (162.2) and glucose (180.2) as a molecule of water is added to a glucan unit during hydrolysis.

$$
\text { Glucan Conversion }(\%)=\frac{m_{\text {glucose }}}{m_{\text {glucan }}} \times 0.90 \times 100 \%
$$

Compositional analysis of different substrates (untreated and pretreated) were analyzed according to the NREL standard procedure No. 002 (2004) that have been developed at the US National Renewable Energy Laboratory (NREL) (Sluiter et al., 2006). The compositions of the different materials used in this study is given in Table 1

Hydrolysis products were measured by high performance liquid chromatography (HPLC). The HPLC analysis was performed with an Agilent Technologies 1200 HPLC system (Santa Clara, CA), with a HPLC carbohydrate analysis column (Biorad Aminex® HPX-87P Column) with $0.2-\mu \mathrm{m}$ filtered reverse osmosis deionized water used as the mobile phase. The flow rate through the system was kept at $0.6 \mathrm{~mL} / \mathrm{min}$ and the column temperature was set to $75^{\circ} \mathrm{C}$. Peak retention times were used as a standard to identify the various sugars that were contained in the samples. Standards were used to create a calibration curve for each sugar that could be present as a product after hydrolysis. A number of concentrations standards were prepared for the different sugars and then analyzed using HPLC. The concentration was then plotted against the respective peak areas and then the data points were fit to a straight line. The 
intercept was set to zero and the slope was used as a calibration constant to then determine the concentrations of sugars in unknown samples. During the sugar analysis the standard curves were made prior to each set of unknown samples along with a standard check being run every 10 samples as a check against drift.

\section{Results and Discussions}

\subsection{Enzymatic Digestibility of a Single Stage Treatment}

The objective in this work will be to first study the effectiveness of the single stage treatments (NMMO, DSA or DPA) on the digestibility of lignocellulosic materials using CTec2. The two treatments will then be used together in a two stage process, first subjected to the dilute acid treatment (DSA or DPA) and then NMMO. The two stage treatment (termed DAWNT Dilute Acid followed with NMMO Treatment) is hypothesized to first remove the cellulose sheathing protecting the major carbohydrate fraction, followed by complete penetration of the solvent into the cellulose for disruption of the hydrogen bonds (Figure 1). This treatment is capable of increasing the enzyme accessibility by increasing both the porosity and the available surface area of the cellulosic matrix.

\subsubsection{Study on the enzymatic digestibility of untreated and NMMO treated lignocellulosic feedstocks}

Enzymatic hydrolysis experiments of SB and CS, with solids loadings of $10 \mathrm{mg} / \mathrm{g}$, were performed at a $\mathrm{pH}$ of 4.9 and $50^{\circ} \mathrm{C}$ at enzyme loadings of $10 \mathrm{mg} \mathrm{g}_{\text {Protein }} / \mathrm{g}_{\mathrm{Glucan}}$ (corresponding to 7.5 FPU/g $\left.\mathrm{g}_{\text {Glucan }}\right)$ in order to quantify their digestibilities before any treatment was applied. The enzymatic hydrolysis results of the untreated and NMMO treated feedstocks are seen in Figure 2. The two untreated lignocellulosic substrates that were studied had only a small portion of their total carbohydrate fractions solubilized into sugars within the first 48 hours: $10.8 \%$ and $19.0 \%$ 
for SB and CS, respectively. Negligible conversions were seen to occur after this time period, pointing to the fact that this material is highly recalcitrant with only a small portion of the carbohydrate fraction being accessible thus reinforcing the need for an effective pretreatment strategy.

Recent studies in literature have investigated the use of NMMO as a pretreatment solvent and have shown that NMMO is effective at breaking up the crystallinity of cellulose (Brodeur et al., 2016) (causing swelling) and that the totality of the material is precipitated once regenerated with water (Poornejad et al., 2011; Shafiei et al., 2010). As can be seen from Table 1, the composition of CS and SB hardly change after NMMO treatment in agreement with these studies. The effect on digestibility of the lignocellulosic materials due to NMMO treatment was next determined by running enzymatic hydrolysis reactions at a $\mathrm{pH}$ of 4.9 and $50^{\circ} \mathrm{C}$ with an enzyme loading of $10 \mathrm{mg}_{\text {Protein }} / \mathrm{g}_{\text {Glucan }}$. The results of hydrolysis for both lignocellulosic feedstocks over 72 hours can be seen in Figure 2 and are plotted in comparison with the untreated materials showing the enhancement due to treatment. The overall glucan conversion and the characteristic rates of hydrolysis were both seen to increase over that of the untreated substrates. Both, CS and SB reached their maximum conversion of $57.9 \%$ and $49.6 \%$ within the first 72 hours, respectively, as no further conversion was seen to occur after this point. Accordingly, a $400 \%$ and $280 \%$ increase in digestibility over the untreated CS and SB was observed. There is, however, a majority of the glucan that was left inaccessible and unconverted as a result of this treatment. The solid lines in Figure 2 are curve fits of the experimental data to the following equation

$$
X_{\text {glucan }}=\frac{X_{\max } t}{\frac{X_{\max }}{R^{\prime}}+t}
$$


where $\mathrm{X}_{\mathrm{glucan}}$ is the glucan conversion (\%), $\mathrm{X}_{\max }$ is the maximum possible glucan conversion and $\mathrm{R}^{\prime}$ is a characteristic rate (\% conversion/h) in the limit as time goes to zero . It has been shown that the above equation is in good agreement in predicting the long term enzymatic hydrolysis conversion of biomass and is also sufficient for estimating the initial hydrolysis rates (Brodeur, 2013; Koullas et al., 1992; O'Dwyer et al., 2007; Ohmine et al., 1983). The advantage of giving a rate in terms of $\%$ conversion/h lies in the ability to compare different reactions run in literature under different conditions. Once $R^{\prime}$ has been calculated, it is straightforward to calculate reactions rates in units of say $\mathrm{mg} / \mathrm{ml} \mathrm{h}$ with known initial biomass concentrations and glucan content. In current work, a constant total solids loading of $10 \mathrm{mg} / \mathrm{g}$ was used and the glucan contents for all substrates is given in Table 1 . The values of $X_{\max }$ and $R^{\prime}$ calculated using Equation 2 are given in Table 2. The characteristic rate $\left(R^{\prime}\right)$ as calculated using Equation 2, were seen to increase by 4.5 -fold, from 1.47 to $7.17 \%$ conv/h and 2.55 to $11.49 \%$ conversion/h, for SB and CS, respectively. This result is promising and illustrates the ability of NMMO to dissolve cellulose resulting in high initial rates. The overall digestibility is still incomplete, however. The hemicellulose-lignin may be blocking the diffusion of the NMMO, hindering its ability to penetrate into the cellulose and preventing complete dissolution. If a disruption of this sheathing was first completed, NMMO may be allowed to penetrate further into the substrate, thus disrupting the hydrogen bonding that is holding the cellulose tightly together and blocking the ability for enzymes to adsorb onto the reactive sites.

\subsubsection{Study of enzymatic digestibility of untreated and dilute acid treated lignocellulosic materials}

Studies in literature have demonstrated the ability of DSA and DPA treatments to effectively disrupt the lignin-hemicellulose sheathing by using a combination of high pressure 
treatment with low concentrations of acids followed by explosive decompression causing fracturing of the fibrous matrix and hydrolyzing the hemicellulose fraction (Geddes et al., 2010; Schell et al., 2003). Enzymatic hydrolysis experiments of dilute sulfuric acid (DSA) treated CS and dilute phosphoric acid (DPA) treated SB with solids loadings of $10 \mathrm{mg} / \mathrm{g}$ were performed at a $\mathrm{pH}$ of 4.9 and $50^{\circ} \mathrm{C}$ at enzyme loadings of $10 \mathrm{mg}_{\text {Protein }} / \mathrm{g}_{\text {Glucan }}\left(7.5 \mathrm{FPU} / \mathrm{g}_{\text {Glucan }}\right)$. Compositional analysis data of the two feedstocks are also presented in Table 1 and it is clear that both the acid treatments remove a majority of the hemicellulose. The enzymatic hydrolysis results of the two feedstocks comparing untreated and dilute acid treatments is seen in

Figure 33. The solid lines are curve fits of Equation 2 with the values of $R^{\prime}$ and $\mathrm{X}_{\max }$ given in Table 2. It was observed that the glucan conversions of both the dilute acid treated feedstocks reached a similar maximum with CS having slightly higher conversions. The 72-hour glucan conversions for SB and CS were observed to reach $80.3 \%$ and $83.6 \%$, respectively. The characteristic rate $\left(R^{\prime}\right)$ of hydrolysis was determined to be $7.81 \%$ conversion/h for DPA treated SB while DSA treated CS was at $10.34 \%$ conversion/h. Similar to NMMO treatment, the characteristic rates have increased due to dilute acid treatment by factors of 5.31 for SB and 4.05 for CS from their respective untreated feedstocks. It is also interesting to note from Table 2 that, even though NMMO and dilute acid treatments have similar $R^{\prime}$, the final conversions are very different with higher conversions for the dilute acid treatments. This high initial rates for NMMO treatment has been attributed to the benefit of swelling of cellulosic substrates which makes cellulose accessible initially but not sufficient to improve long term conversions. Both DSA and DPA treatments show that the removal of hemicellulose yields a cellulose fraction that is $\sim 80$ $90 \%$ digestible over time; however there is some fraction of the cellulose that still not completely 
digestible. Upwards of $15 \%$ of the cellulosic fraction and generally higher will not be converted at reasonable times of hydrolysis. This can pose a problem when trying to commercialize a process that needs to be economical. Literature data for a variety of DA treatments has given the same results as far as the inability to create a completely accessible substrate (Jensen et al., 2010; Schell et al., 2003; Silverstein et al., 2007; Um et al., 2003). So the question remains as to how to maximize the carbohydrate digestibility economically. One needs to do this by increasing the cellulose accessibility without excessive treatments and at the same time limit the enzyme loading requirement.

\subsection{Study of enzymatic digestibility of a novel multi-stage treatment (DAWNT)}

The advantages of the single stage treatments have clearly been defined in the previous sections. The DA treatment has the capability to hydrolyze the majority of the hemicellulose fraction while also disrupting the biomass structure. The NMMO treatment is able to create a highly swollen substrate, significantly increasing surface area and maximizing the enzymatic digestibility of the accessible cellulose resulting in high initial rates. Combining these two treatments will allow for the removal of the hemicellulose in the first stage thus allowing the cellulosic fraction to be penetrated by the NMMO more readily in second; yielding a completely digestible cellulosic fraction. This is a milestone that has yet to be fully achieved at these processing conditions and enzyme loadings for a lignocellulosic substrate and is the hypothesis for current work.

During treatment, the dilute acid treated materials were seen to be completely dissolved by NMMO within the first 20 minutes of treatment. This does not occur with a true lignocellulosic material owing to the hindrance on the ability for NMMO to penetrate the highly complex lignocellulosic structure, only dissolving a portion of the exposed cellulose. Once 
treatment was concluded, the DAWNT-substrate-NMMO monohydrate solution was gently poured into the anti-solvent solution (DI water) where the material was quickly precipitated as the NMMO, being highly hydrophilic, was then solubilized in the water. The composition of materials treated with NMMO has been shown to not change as a result of the treatment as has been shown in this work and others (Shafiei et al., 2010). To see if the composition of the biomass changes after DA followed by a NMMO treatment, the composition of CS treated with DA and with DAWNT was tested according to the NREL standard compositional analysis method. The results of this test can be seen in Table 1. The relative composition of the material was observed to have no change as a result of the additional treatment with NMMO, as is expected. The second treatment is still only seen to have a physical action on the material as it is dissolved and regenerated.

Enzymatic hydrolysis experiments were then performed on both SB and CS that had been treated by both dilute acid and NMMO in a step-wise process (DAWNT). The enzymatic hydrolysis conditions were kept consistent for all samples for comparison purpose: solids loadings of $10 \mathrm{mg} / \mathrm{g}, \mathrm{pH}$ of 4.9 , temperature of $50^{\circ} \mathrm{C}$, and enzyme loadings of $10 \mathrm{mg} \mathrm{P}_{\text {Protein }} / \mathrm{g}_{\text {Glucan }}$ (7.5 FPU/g $\mathrm{g}_{\text {Glucan }}$ ). A comparison of the glucan conversions as a function of time for CS and SB for all treatments performed can be seen in Error! Reference source not found.4a and Figure $4 \mathrm{~b}$ respectively. The single stage treatments for each of the respective materials are also plotted on the same figures to show the enhancement in digestibility when adding the additional stage. The lines in Figure $4 \mathrm{a}$ and $4 \mathrm{~b}$ are curve fits of Equation 2 with values of $\mathrm{X}_{\max }$ and $R^{\prime}$ given in Table 2 .

When the two stage treatment (DAWNT) is applied in both cases (SB, CS) the rates of hydrolysis and overall yields are seen to dramatically improve, while keeping all other conditions 
constant. A beneficial finding in this study is the fact that with the added NMMO treatment (3 h), 48 hours can be taken off the time of hydrolysis and reach similar conversions. For dilute acid treated CS the conversion after $72 \mathrm{~h}$ is $83 \%$ while the same conversion for DAWNT CS is only $24 \mathrm{~h}-$ a reduction of $48 \mathrm{~h}$. This is depicted by the solid line in Figure 4a. This would substantially improve the economics of any conversion process that needs to lower costs at any point during processing. Additional costs associated with the added treatment step in terms of separation process, capital investment costs due to necessary equipment, and the need for solvent recovery may all play a role in determining the overall economics. However this needs further investigation in order to provide any quantitative information on its economic benefit and will be the subject of future work.

Furthermore, the 72 hour glucan conversions were seen to be improved for SB from $80.3 \%$ to $91.5 \%$ and for CS from $83.6 \%$ to $98.3 \%$ when additional NMMO treatment step was added. This represents a relative increase in digestibility over the DA treatments by $13.9 \%$ in the case of SB and $17.6 \%$ increase for CS. The increase in digestibility over NMMO treatment was significantly improved from $52.9 \%$ to $91.5 \%$ for SB and $62.1 \%$ to $98.3 \%$ for CS when the majority of hemicellulosic fraction was first removed; representing an increase of $73.0 \%$ and $58.3 \%$ for SB and CS, respectively. A comparison of the results obtained from current work with data from literature is given in Figure 5. Glucan conversion for enzymatic hydrolysis of different pretreated (dilute acid and solvent based) substrates (solid boxes) and the corresponding enzyme loading (shaded boxes) are given in Figure 5. The time at which the glucan conversion is given is also given in the same figure. Results from the current work are plotted on the same graph and as mentioned above DAWNT results in a higher conversion at reduced times and also 
at reduced enzyme loadings. An enzyme loading of just $7.5 \mathrm{FPU} / \mathrm{g}$ glucan was used in current work which would result in substantial cost savings.

The increase observed between characteristic rates and calculated maximum conversions for the treatments studied is easily seen by looking at Figure 6. The dilute acid and NMMO treatments have similar characteristic rates, while the DA is far superior in terms of maximum obtainable conversion. The two-stage treatment shows a 2-fold increase in characteristic rates over the single-stage treatments while also having the ability to almost completely digest the carbohydrate fraction. In all cases, the observed characteristic rates and maximum conversions for CS were higher than that of SB possibly due to the lower recalcitrance of the material.

There are a few aspects of the two-stage treatment that may prove advantageous if the conditions were reduced and therefore lowering the economic input that will be needed. These include solids loading during hydrolysis, enzyme loading, as well as NMMO treatment time. To explore these issues, experiments were run with solids loadings $10-50 \mathrm{mg}$ biomass/g total solution, enzyme loadings from $3.3-10 \mathrm{mg}_{\text {protein }} / \mathrm{g}_{\text {Glucan }}$, and NMMO treatment time from $1-3$ hours. Tabulated data consisting of characteristic rates, maximum conversions, and maximum calculated conversions are also given for all conditions in Table 3. For SB, the only condition tested was for increased solids loading (10 to $50 \mathrm{mg} / \mathrm{g}$ ) during hydrolysis. What can be taken away from these results is that the same efficiency is seen as far as digestibility during hydrolysis. The characteristic rate is slightly increased from $16.83 \%$ conversion/h to 17.35 $\%$ conversion/h. The $72 \mathrm{~h}$ conversion was slightly reduced from $91.5 \%$ to $89.9 \%$; nevertheless the material was nearly completely digested $(98.3 \%)$ when the reaction was finally stopped at 150 hours. The adjustment of conditions for the treatments with CS was also seen to have promising features. Overall, the digestibility of the materials were all observed to well-surpass 
$80 \%$ within 72 hours, noted for being the conversion of a single stage DA treatment of the same material. The maximum digestibility observed during experimentation all exceeded $90 \%$ conversion. Further investigation into the effects of these parameters on their influence of both rates and digestibility, along with a full-scale economic analysis is needed before any definite conclusions can be made as to precise optimal processing conditions.

The ability to alter the treatment time of recycled NMMO was also investigated to see if the NMMO remained as effective at shorter contact times. The characteristic rates, digestibility at 72 hours, and calculated maximum conversions are shown in Table 4. Little change is observed when the treatment time is reduced from 3 hours to 1 hour at all of the cycles of NMMO reuse. Inconclusive patterns were observed for NMMO recycle, but this is attributed to variance in experimentation as the trials for each recycle were run simultaneously. This is a very promising result that demonstrates that recycled NMMO has the same efficacy when used for pretreatment and that just $1 \mathrm{~h}$ treatment is sufficient in most instances.

\section{Conclusions}

When the dual stage treatment is applied to both $\mathrm{CS}$ and $\mathrm{SB}$, the rates of hydrolysis and overall yields are seen to dramatically improve and that 48 hours can be taken off the time of hydrolysis to reach similar conversions when compared to a single stage treatment. DAWNT utilizes a lower enzyme loading and shows a 2 -fold increase in characteristic rates while also having the ability to almost completely digest the carbohydrate fraction. In addition, the twostage treatment fractionates different components of biomass. Future work will focus on developing an economic analysis of DAWNT for use in biomass fractionation.

\section{Acknowledgements}


Funding for this research was provided by the Southeastern SunGrant Center, a program supported by the US Department of Transportation. Additional funding was provided by the U.S. Department of Energy under Contract No. DE-AC36-08-GO28308 with the National Renewable Energy Laboratory and through the Bioenergy Technologies Office. S. Ramakrishnan and J. Telotte would also like to thank Bush Brothers for partial financial support. 


\section{References}

Bansal, P., Vowell, B.J., Hall, M., Realff, M.J., Lee, J.H., Bommarius, A.S. 2012. Elucidation of cellulose accessibility, hydrolysability and reactivity as the major limitations in the enzymatic hydrolysis of cellulose. Bioresource Technology, 107, 243-250.

Bradford, M. 1976. A rapid and sensitive method for the quantification of microgram quantities of protein utilizing the principle of protein-dye binding. Analytical Biochemistry, 72, 248254.

Brodeur, G. 2013. Developing a novel two stage pretreatment of lignocellulosic biomass for enhanced bioprocessing. in: Deparetment of Chemical and Biomedical Engineering, Vol. Ph.D. Thesis, Florida State University.

Brodeur, G., Yau, E., Badal, K., Collier, J., Ramachandran, K.B., Ramakrishnan, S. 2011. Chemical and physicochemical pretreatment of lignocellulosic biomass: a review. Enzyme research, 2011, 787532-787532.

Brodeur, G., Yau, E., Collier, J., Telotte, J., Ramakrishnan, S. 2016. Effect of solids loading and solvent type on the enzymatic hydrolysis of cellulose. Journal of Chemical Technology \& Biotechnology, n/a-n/a.

Collier, J.R., Collier, B., Negulescu, I. 2003. Cellulosic Microfibers. US Patent 6,511,746 B1

Dadi, A.P., Schall, C.A., Varanasi, S. 2007. Mitigation of cellulose recalcitrance to enzymatic hydrolysis by ionic liquid pretreatment. Applied Biochemistry and Biotechnology, 137, 407-421.

Dadi, A.P., Varanasi, S., Schall, C.A. 2006. Enhancement of cellulose saccharification kinetics using an ionic liquid pretreatment step. Biotechnology and Bioengineering, 95(5), 904910.

Geddes, C.C., Peterson, J.J., Roslander, C., Zacchi, G., Mullinnix, M.T., Shanmugam, K.T., Ingram, L.O. 2010. Optimizing the saccharification of sugar cane bagasse using dilute phosphoric acid followed by fungal cellulases. Bioresource Technology, 101(6), 18511857.

Geddes, R., Shanmugam, K.T., Ingram, L.O. 2015. Combining treatments to improve the fermentation of sugarcane bagasse hydrolysates by ethanologenic Escherichia coli LY180. Bioresource Technology, 189, 15-22.

Ghose, T.K. 1987. Measurement of cellulase activities. Pure \& Applied Chemistry, 59(2), 257268.

Jackson de Moraes Rocha, G., Martin, C., Soares, I.B., Souto Maior, A.M., Baudel, H.M., Moraes de Abreu, C.A. 2011. Dilute mixed-acid pretreatment of sugarcane bagasse for ethanol production. Biomass and Bioenergy, 35(1), 663-670.

Jeihanipour, A., Karimi, K., Taherzadeh, M.J. 2010. Enhancement of ethanol and biogas production from high-crystalline cellulose by different modes of NMO pretreatment. Biotechnology and Bioengineering, 105(3), 469-476.

Jensen, J.R., Morinelly, J.E., Gossen, K.R., Brodeur-Campbell, M.J., Shonnard, D.R. 2010. Effects of dilute acid pretreatment conditions on enzymatic hydrolysis monomer and oligomer sugar yields for aspen, balsam, and switchgrass. Bioresource Technology, 101(7), 2317-2325. 
Koullas, D.P., Christakopoulos, P., Kekos, D., Macris, B.J., Koukios, E.G. 1992. Correlating the effect of pretreatment on the enzymatic hydrolysis of straw. Biotechnology and Bioengineering, 39(1), 113-116.

Kumar, P., Barrett, D.M., Delwiche, M.J., Stroeve, P. 2009. Methods for preteratment of lignocellulosic biomass for efficient hydrolysis and biofuel production. Ind. Eng. Chem. Res., 48, 3713-3729.

Kuo, C.H., Lee, C.K. 2009. Enhancement of enzymatic saccharification of cellulose by cellulose dissolution pretreatments. Carbohydrate Polymers, 77(1), 41-46.

Lennartsson, P., Niklasson, C., Taherzadeh, M. 2011. A pilot study on lignocelluloses to ethanol and fish feed using NMMO pretreatment and cultivation with zygomycetes in an air-lift reactor. Bioresource Technology, 102(6), 4425-32.

Li, C., Knierim, B., Manisseri, C., Arora, R., Scheller, H.V., Auer, M., Vogel, K.P., Simmons, B.A., Singh, S. 2010. Comparison of dilute acid and ionic liquid pretreatment of switchgrass: Biomass recalcitrance, delignification and enzymatic saccharification. Bioresource Technology, 101(13), 4900-4906.

O'Dwyer, J.P., Zhu, L., Granda, C.B., Holtzapple, M.T. 2007. Enzymatic hydrolysis of limepretreated corn stover and investigation of the $\mathrm{HCH}-1$ Model: Inhibition pattern, degree of inhibition, validity of simplified HCH-1 Model. Bioresource Technology, 98(16), 2969-2977.

Ohmine, K., Ooshima, H., Harano, Y. 1983. Kinetic study on enzymatic hydrolysis of cellulose by cellulose from Trichoderma viride. Biotechnology and Bioengineering, 25(8), 20412053.

Petrovan, S., Collier, J.R., Negulescu, I. 2001. Rheology of cellulosic N-methylmorpholine oxide monohydrate solutions of different degrees of polymerization. Journal of Applied Polymer Science, 79(3), 396-405.

Poornejad, N., Karimi, K., Behzad, T. 2011. Improvement of saccharification and ethanol production from rice straw by NMMO and [BMIM][OAc] pretreatments. Industrial Crops and Products, 41(0), 408-413.

Ramakrishnan, S., Collier, J., Oyetunji, R., Stutts, B., Burnett, R. 2010. Enzymatic hydrolysis of cellulose dissolved in $\mathrm{N}$-methyl morpholine oxide/water solutions. Bioresource Technology, 101(13), 4965-4970.

Sawisit, A., Jantama, K., Zheng, H., Yomano, L.P., York, S.W., Shanmugam, K.T., Ingram, L.O. 2015. Mutation in galP improved fermentation of mixed sugars to succinate using engineered Escherichia coli AS1600a and AM1 mineral salts medium. Bioresource Technology, 193, 433-441.

Schell, D.J., Farmer, J., Newman, M., McMillan, J.D. 2003. Dilute-sulfuric acid pretreatment of corn stover in pilot-scale reactor. Applied Biochemistry and Biotechnology, 105-108.

Shafiei, M., Karimi, K., Taherzadeh, M.J. 2010. Pretreatment of spruce and oak by Nmethylmorpholine-N-oxide (NMMO) for efficient conversion of their cellulose to ethanol. Bioresource Technology, 101(13), 4914-4918.

Silverstein, R.A., Chen, Y., Sharma-Shivappa, R.R., Boyette, M.D., Osborne, J. 2007. A comparison of chemical pretreatment methods for improving saccharification of cotton stalks. Bioresource Technology, 98(16), 3000-3011.

Sluiter, A., Hames, B., Ruiz, R., Scarlata, C., Sluiter, J., Templeton, D., Crocker, D. 2006. NREL analytical procedure, determination of stuctural carbohydrates and lignin in biomass. in: 
National Renewable Energy Laboratory, Website: http://devafdc.nrel.gov/pdfs/9572.pdf. Golden, CO.

Tian, S., Zhu, W., Gleisner, R., Pan, X.J., Zhu, J.Y. 2011. Comparisons of SPORL and dilute acid pretreatments for sugar and ethanol productions from aspen. Biotechnology Progress, 27(2), 419-427.

Um, B.H., Karim, M.N., Henk, L.L. 2003. Effect of sulfuric and phosphoric acid pretreatments on enzymatic hydrolysis of corn stover. Applied Biochemistry and Biotechnology, 105, $115-125$.

Vahid, J., Labafzadeh, S.R., Jeihanipour, A., Karimi, K., Taherzadeh, M.J. 2011. Construction and demolition lignocellulosic wastes to bioethanol. Renewable Energy, 36, 2771-2775.

Wang, K., Yang, H.Y., Xu, F., Sun, R.C. 2011. Structural comparison and enhanced enzymatic hydrolysis of the cellulosic preparation from Populus tomentosa Carr., by different cellulose-soluble solvent systems. Bioresource Technology, 102(6), 4524-4529.

Wang, X., Yomano, L.P., Lee, J.Y., York, S.W., Zheng, H., Mullinnix, M.T., Shanmugam, K.T., Ingram, L.O. 2013. Engineering furfural tolerance in Escherichia coli improves the fermentation of lignocellulosic sugars into renewable chemicals. Proceedings of the National Academy of Sciences of the United States of America, 110(10), 4021-4026.

Wyman, C.E., Balan, V., Dale, B.E., Elander, R.T., Falls, M., Hames, B., Holtzapple, M.T., Ladisch, M.R., Lee, Y.Y., Mosier, N., Pallapolu, V.R., Shi, J., Thomas, S.R., Warner, R.E. 2011. Comparative data on effects of leading pretreatments and enzyme loadings and formulations on sugar yields from different switchgrass sources. Bioresource Technology, 102(24), 11052-11062.

Yoon, L.W., Ngoh, G.C., May Chua, A.S., Hashim, M.A. 2011. Comparison of ionic liquid, acid and alkali pretreatments for sugarcane bagasse enzymatic saccharification. Journal of Chemical Technology \& Biotechnology, 86(10), 1342-1348. 


\section{Figure and Table Captions}

Table 1: Compositional analysis of the different materials used in this work. CS- corn stover, SB - sugarcane bagasse, NMMO - N methyl Morpholine N oxide, DSA - dilute sulfuric acid, DAWNT - dilute acid followed by NMMO treatment, DPA- dilute phosphoric acid.

Table 2: Characteristic rates of hydrolysis, maximum experimental conversions, and maximum theoretical conversions (Equation 2) for the enzymatic hydrolysis of the materials indicated.

Table 3: Experimentally observed initial rates, calculated characteristic rates of hydrolysis, maximum experimental conversions (digestibility), and maximum theoretical conversions for DAWNT-SB and -CS at various NMMO treatment times and solids loadings during hydrolysis. NTT: NMMO treatment time (h); SL: solids loading ( $\mathrm{mg}_{\text {biomass }} / \mathrm{g}$ total solution); E: enzyme loading $\left(\mathrm{mg}_{\text {protein }} / \mathrm{g}_{\text {Glucan }}\right)$.

Table 4: Characteristic rates of hydrolysis, maximum experimental conversions, and maximum theoretical conversions (Equation 2) for DAWNT-CS using recycled NMMO at different treatment times.

Figure 1: Schematic of the DAWNT process. The basis of the mass balance is $100 \mathrm{~g}$ of dilute acid treated biomass. The elemental analysis of the different streams (as indicated by the number in superscript) are given in table 1 . Two different acid treatments were used in this work -1 ) dilute sulfuric acid followed by steam explosion ( 1 minute retention times at $190^{\circ} \mathrm{C}$ and an acid concentration of $0.5 \% \mathrm{w} / \mathrm{w} \mathrm{H}_{2} \mathrm{SO}_{4}$ ) for corn stover and 2) dilute phosphoric acid followed by 
steam explosion (5 minute retention time at $190^{\circ} \mathrm{C}$ and an acid concentration of $0.5 \% \mathrm{w} / \mathrm{w}$ phosphoric acid) four sugarcane bagasse. NMMO treatment consisted of dissolution of solids in NMMO at $100^{\circ} \mathrm{C}$ for three hours. Composition of the different streams is given in Table 1.

Figure 2: Glucan conversion as a function of time for the enzymatic hydrolysis of: (०) untreated sugarcane bagasse, $(\square)$ untreated corn stover, $(\bullet)$ NMMO treated sugarcane bagasse, (匹) NMMO treated corn stover.

Figure 3: Glucan conversion as a function of time for the enzymatic hydrolysis of: (०) untreated sugarcane bagasse, $(\square)$ untreated corn stover, $(\bullet)$ DPA treated sugarcane bagasse, ( DSA treated corn stover.

Figure 4a: Glucan conversion as a function of time for the enzymatic hydrolysis of: ( $\mathbf{\nabla})$ untreated, ( $(\mathbf{\Delta})$ NMMO treated, $(\bullet)$ dilute acid treated and (•) DAWNT treated corn stover.

Figure 4b: Glucan conversion as a function of time for the enzymatic hydrolysis of: (-) untreated, $(\boldsymbol{\nabla})$ NMMO treated, $(\boldsymbol{\Delta})$ dilute acid treated and $(\bullet)$ DAWNT treated sugarcane bagasse.

Figure 5: Glucan conversion (\%) for different pretreated substrates at a fixed time of enzymatic hydrolysis. The solid boxes are the glucan conversion (\%) and the shaded boxes are the enzyme loading used during hydrolysis. Data from literature is compared with results from current work to illustrate the enhanced yields observed at reduced enzyme loadings. 
Figure 6: Characteristic rates plotted against the calculated maximum conversions for all treatments of ( $\square$ ) sugarcane bagasse and ( $\boldsymbol{\square})$ corn stover. 
Table 1

\begin{tabular}{|c|c|c|c|c|c|c|c|c|}
\hline $\begin{array}{c}\text { Treatment/ } \\
\text { Material }\end{array}$ & $\begin{array}{c}\text { Glucan } \\
\%\end{array}$ & $\begin{array}{c}\text { Xylan } \\
\%\end{array}$ & $\begin{array}{c}\text { Galactan } \\
\%\end{array}$ & $\begin{array}{c}\text { Arabinan } \\
\%\end{array}$ & $\begin{array}{c}\text { Total } \\
\text { Lignin } \\
\%\end{array}$ & $\begin{array}{c}\text { Ash } \\
\%\end{array}$ & $\begin{array}{c}\text { Acetyl } \\
\%\end{array}$ & $\begin{array}{c}\text { Total } \\
\%\end{array}$ \\
\hline Untreated CS & 40.9 & 26.9 & 1.4 & 3.3 & 17.3 & 2.8 & 3.7 & 96.3 \\
\hline $\begin{array}{c}\text { NMMO treated } \\
\text { CS }\end{array}$ & 39.6 & 25 & 1.3 & 3.1 & 20.8 & 2.9 & 2.8 & 95.5 \\
\hline $\begin{array}{c}{ }^{1} \text { DSA treated } \\
\text { CS }\end{array}$ & 59.5 & 3.4 & 0.8 & 0.9 & 29.6 & 3.6 & 0.6 & 98.4 \\
\hline${ }^{2}$ DAWNT CS & 60.7 & 7 & 1.3 & 1.3 & 26.6 & 5.5 & 0.2 & 101.6 \\
\hline $\begin{array}{c}{ }^{3} \text { Solubilized } \\
\text { Cellulose (CS) }\end{array}$ & 92.6 & 4.5 & 1.2 & 1.3 & & & & 99.6 \\
\hline $\begin{array}{c}{ }^{4} \text { Residual Solid } \\
\text { (CS) }\end{array}$ & 9.2 & 8.4 & 0.8 & 0.8 & 80.7 & & & 99.9 \\
\hline Untreated SB & 41.6 & 21.7 & 1.9 & 2.4 & 28.9 & ND & ND & 96.8 \\
\hline $\begin{array}{c}\text { NMMO treated } \\
\text { SB }\end{array}$ & 39.9 & 19.8 & 2.1 & 2.2 & 31.2 & ND & ND & 95.2 \\
\hline $\begin{array}{c}{ }^{1} \text { DPA treated } \\
\text { SB }\end{array}$ & 58.3 & 6.4 & 2 & 1.9 & 26.8 & ND & ND & 95.4 \\
\hline${ }^{2}$ DAWNT SB & 59.7 & 6.2 & 1.2 & 1.1 & 25.6 & ND & ND & 93.8 \\
\hline $\begin{array}{c}{ }^{3} \text { Solubilized } \\
\text { Cellulose (SB) }\end{array}$ & 91.1 & 5.9 & 1.6 & 1.4 & & & & 100 \\
\hline $\begin{array}{c}{ }^{4} \text { Residual Solid } \\
\text { (SB) }\end{array}$ & 9.5 & 7.8 & 0.8 & 0.8 & 81.2 & & & 100.1 \\
\hline
\end{tabular}

ND - not determined in current work 
Table 2

\begin{tabular}{lccc}
\hline $\begin{array}{c}\text { Feedstock } \\
\text { Treatment }\end{array}$ & $\begin{array}{c}\text { Characteristic Rate, } \boldsymbol{R}^{\prime} \\
(\boldsymbol{\%} \text { conversion } / \cdot \mathbf{h})\end{array}$ & $\begin{array}{c}\text { Exp. Max. } \\
\text { Conversion } \\
(\boldsymbol{\%})\end{array}$ & $\begin{array}{c}\text { Calc. Max. Conversion, } \\
\boldsymbol{X}_{\text {max }}(\boldsymbol{\%})\end{array}$ \\
\hline Sugarcane Bagasse & & & \\
\hdashline Untreated & 1.47 & $12.5(72 \mathrm{~h})$ & 13.6 \\
NMMO & 7.17 & $49.6(72 \mathrm{~h})$ & 52.8 \\
DPA & 7.81 & $80.3(72 \mathrm{~h})$ & 85.6 \\
DAWNT & 24.37 & $91.5(72 \mathrm{~h})$ & 95.5 \\
\hline Corn Stover & & & \\
\hdashline Untreated & 2.55 & $20.7(72 \mathrm{~h})$ & 22.6 \\
NMMO & 11.49 & $57.9(72 \mathrm{~h})$ & 61.1 \\
DSA & 10.34 & $83.6(72 \mathrm{~h})$ & 92.1 \\
DAWNT & 19.51 & $98.3(72 \mathrm{~h})$ & 98.9 \\
\hline
\end{tabular}


Table 3

\begin{tabular}{|c|c|c|c|c|c|}
\hline $\begin{array}{c}\text { NTT } \\
(\mathbf{h})\end{array}$ & $\begin{array}{c}\text { Conditions } \\
\text { SL } \\
(\mathrm{mg} / \mathrm{g}) \\
\end{array}$ & $\begin{array}{c}\mathrm{E} \\
(\mathrm{mg} / \mathrm{g})\end{array}$ & $\begin{array}{c}\text { Characteristic } \\
\text { Rate, } \boldsymbol{R}^{\prime} \\
(\% \text { conversion/h) }\end{array}$ & $\begin{array}{c}\text { Exp. Max. } \\
\text { Conversion } \\
(\%) \\
\end{array}$ & $\begin{array}{c}\text { Calc. Max } \\
\text { Conversion, } \\
X_{\max }(\%)\end{array}$ \\
\hline \multicolumn{6}{|c|}{ Sugarcane Bagasse } \\
\hline 3 & 10 & 10 & 16.83 & 91.5 (72 h) & 95.5 \\
\hline 3 & 50 & 10 & 17.35 & $\begin{array}{c}89.9(72 \mathrm{~h}) \\
98.3(150 \mathrm{~h})\end{array}$ & 91.3 \\
\hline \multicolumn{6}{|c|}{ Corn Stover } \\
\hline 3 & 10 & 10 & 24.23 & $98.3(72 \mathrm{~h})$ & 99.5 \\
\hline 1 & 10 & 10 & 38.63 & $97.1(72 \mathrm{~h})$ & 98.1 \\
\hline 1 & 50 & 10 & 26.21 & $\begin{array}{c}98.2(72 \mathrm{~h}) \\
99.1(150 \mathrm{~h})\end{array}$ & 99.3 \\
\hline 3 & 10 & 6.6 & 15.46 & $\begin{array}{c}92.0(72 \mathrm{~h}) \\
99.5(120 \mathrm{~h})\end{array}$ & 99.3 \\
\hline 1 & 10 & 6.6 & 15.07 & $\begin{array}{c}84.7(72 \mathrm{~h}) \\
92.0(120 \mathrm{~h})\end{array}$ & 93.0 \\
\hline 3 & 15 & 6.3 & 6.46 & $\begin{array}{c}84.4(72 \mathrm{~h}) \\
91.2(120 \mathrm{~h})\end{array}$ & 93.4 \\
\hline
\end{tabular}


Table 4

\begin{tabular}{|c|c|c|c|c|}
\hline $\begin{array}{l}\text { NMMO } \\
\text { Recycles }\end{array}$ & $\begin{array}{l}\text { NMMO } \\
\text { Treatment } \\
\text { Time (h) }\end{array}$ & $\begin{array}{c}\text { Characteristic } \\
\text { Rate, } \boldsymbol{R}^{\prime} \\
(\% \text { conversion } / \mathbf{h})\end{array}$ & $\begin{array}{l}\text { Exp. Max. } \\
\text { Conversion } \\
(\% \text { at } 72 \text { h) }\end{array}$ & $\begin{array}{c}\text { Calculated } \\
\text { Max } \\
\text { Conversion, } \\
X_{\max }(\%) \\
\end{array}$ \\
\hline \multirow{2}{*}{1} & 1 & 24.27 & 98.1 & 99.2 \\
\hline & 3 & 24.63 & 98.9. & 99.1 \\
\hline \multirow{2}{*}{2} & 1 & 41.29 & 92.1 & 89.1 \\
\hline & 3 & 38.59 & 94.8 & 92.3 \\
\hline \multirow{2}{*}{3} & 1 & 33.95 & 98.1 & 97.3 \\
\hline & 3 & 35.22 & 96.0 & 94.9 \\
\hline
\end{tabular}


Figure 1

DAWNT (dilute acid followed by NMMO treatment)

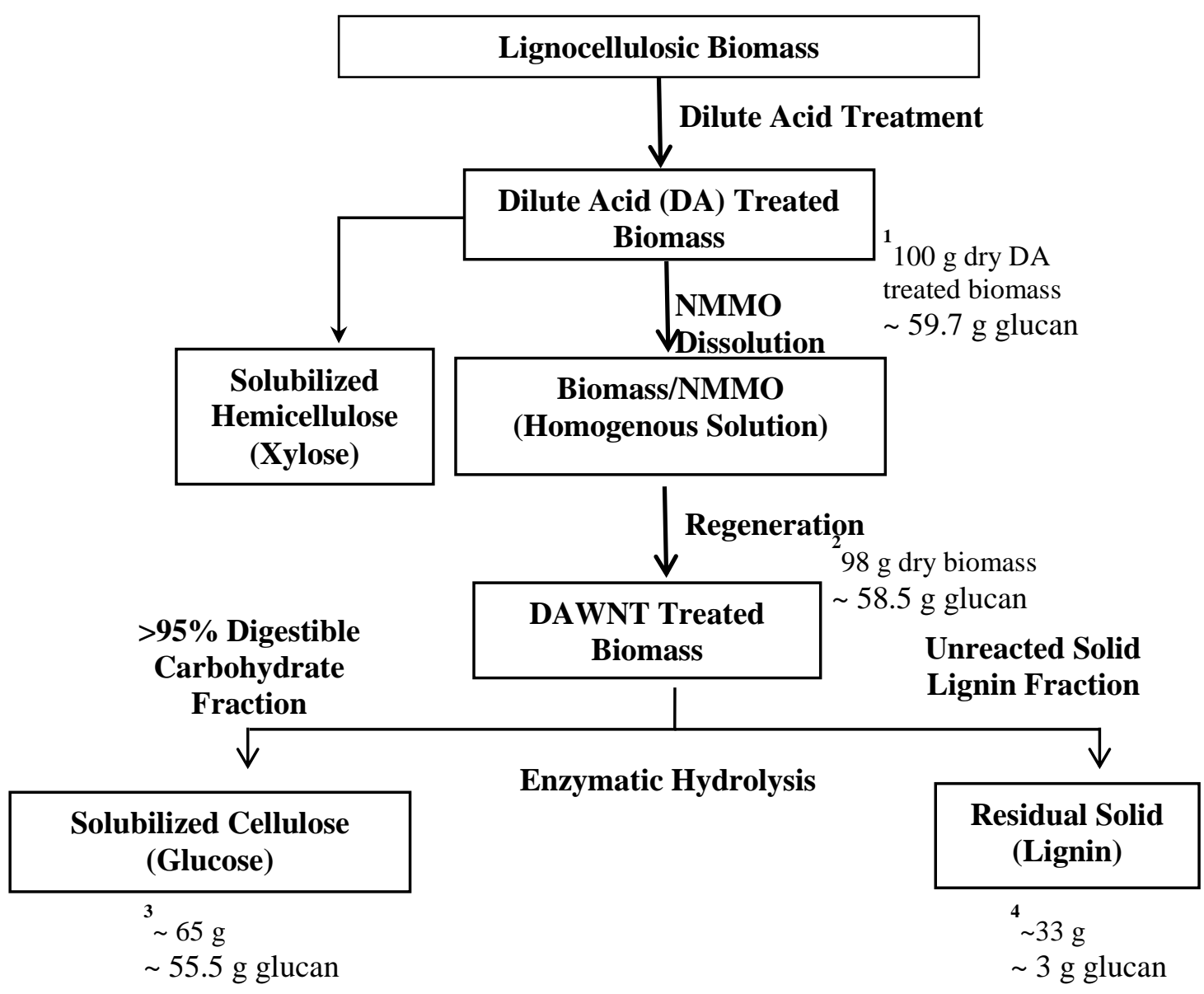




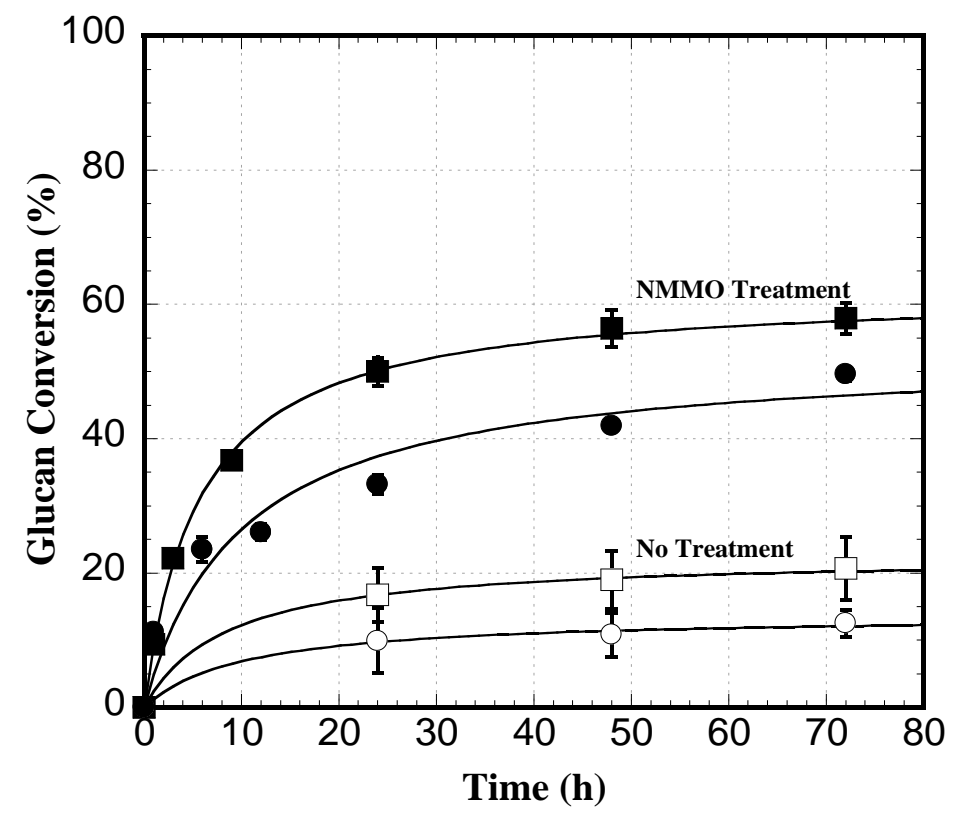

Figure 2 


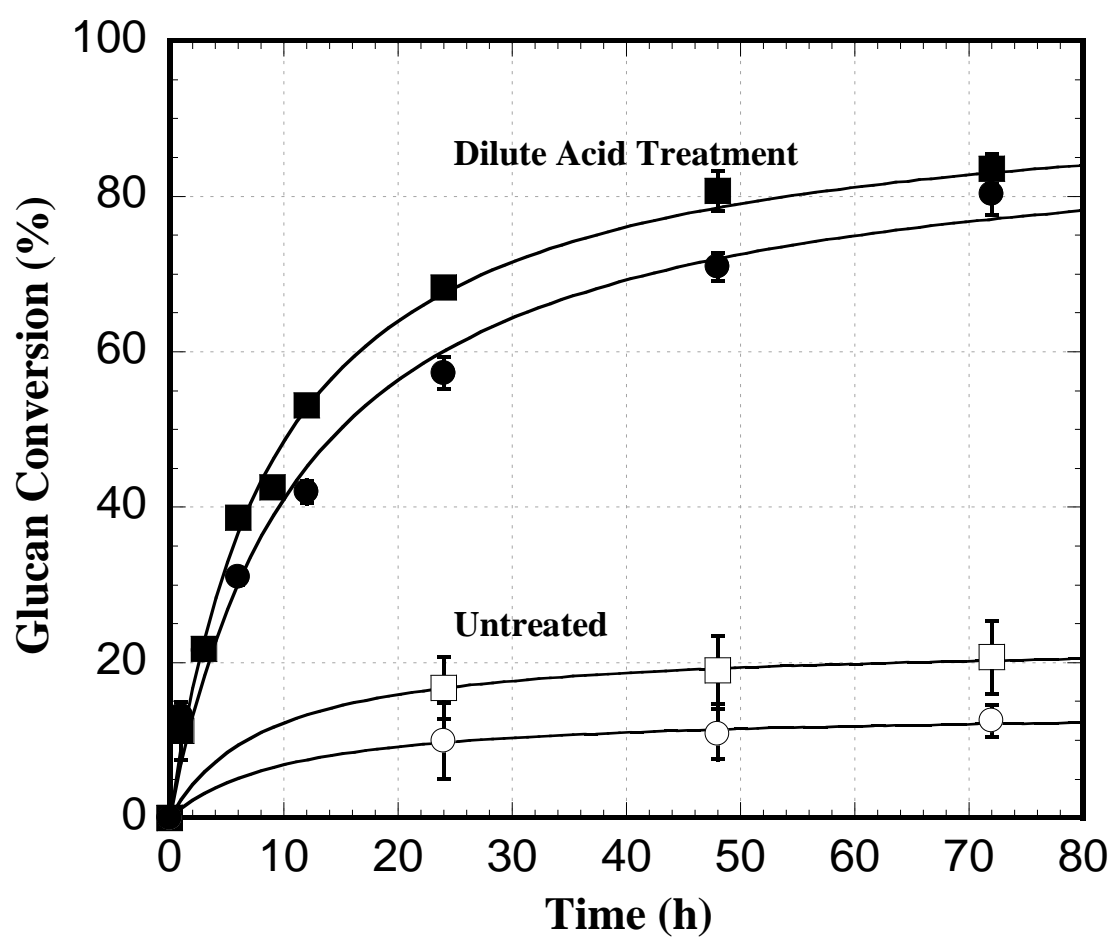

Figure 3 


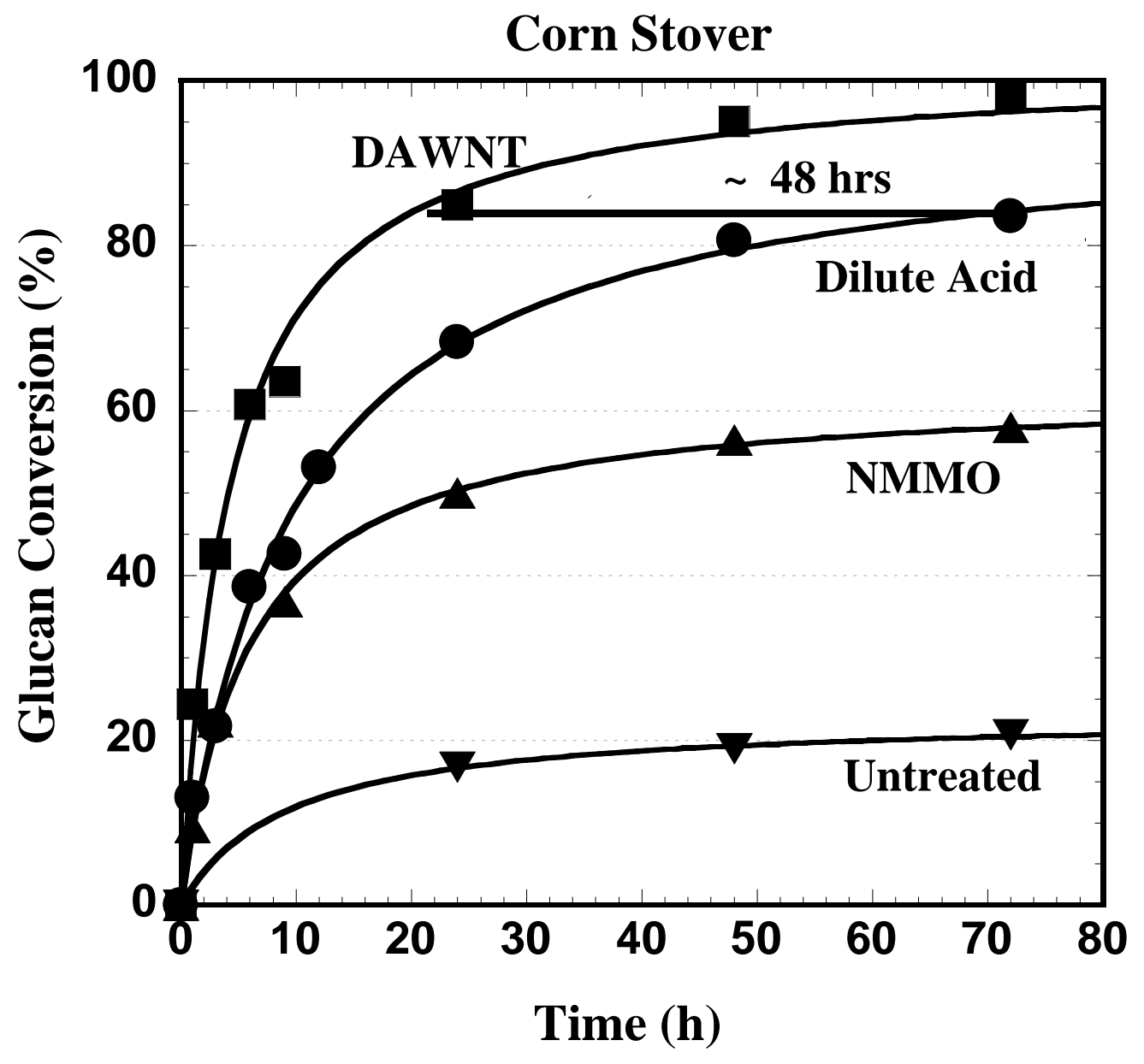

Figure 4a 


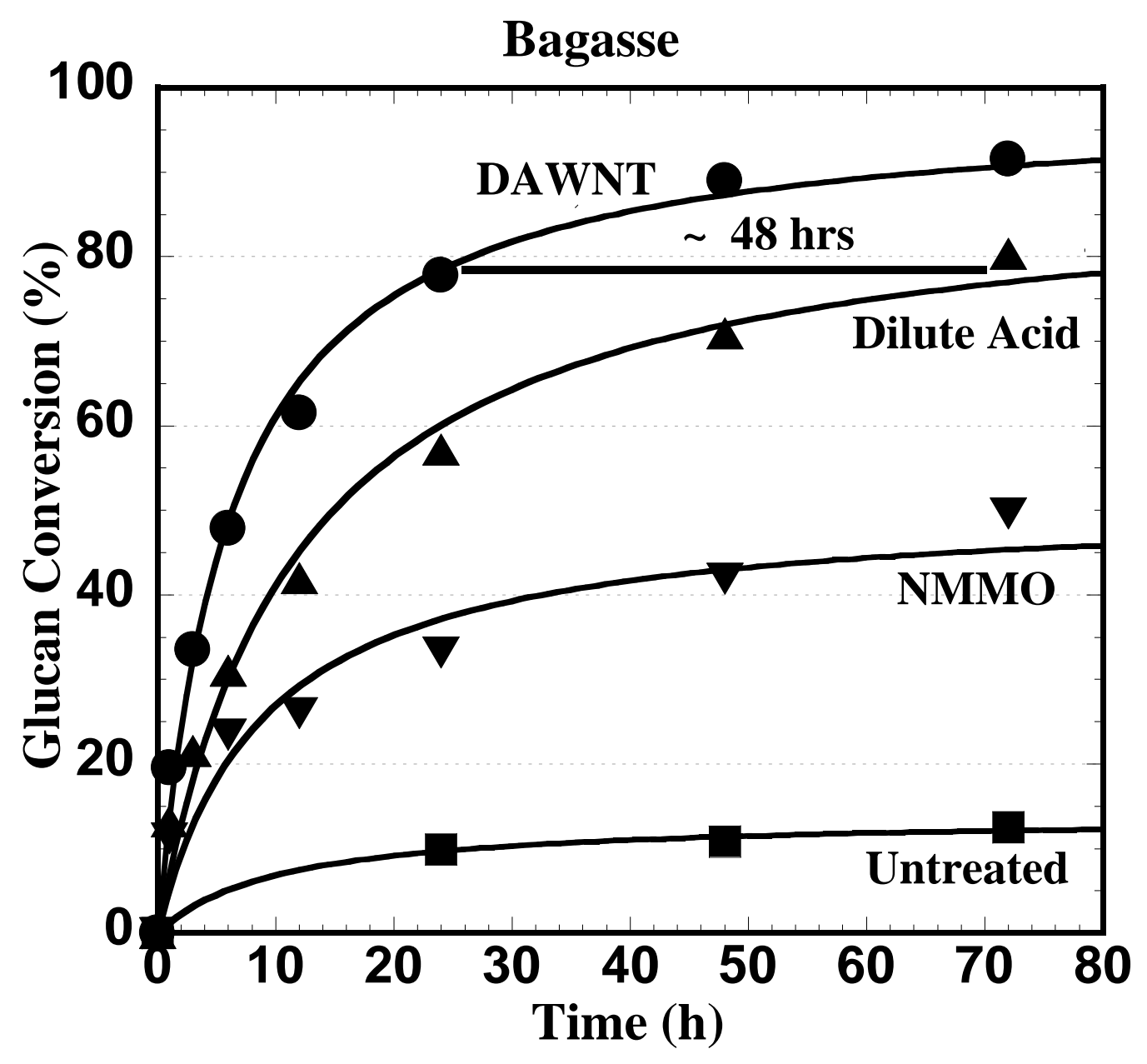

Figure 4b 


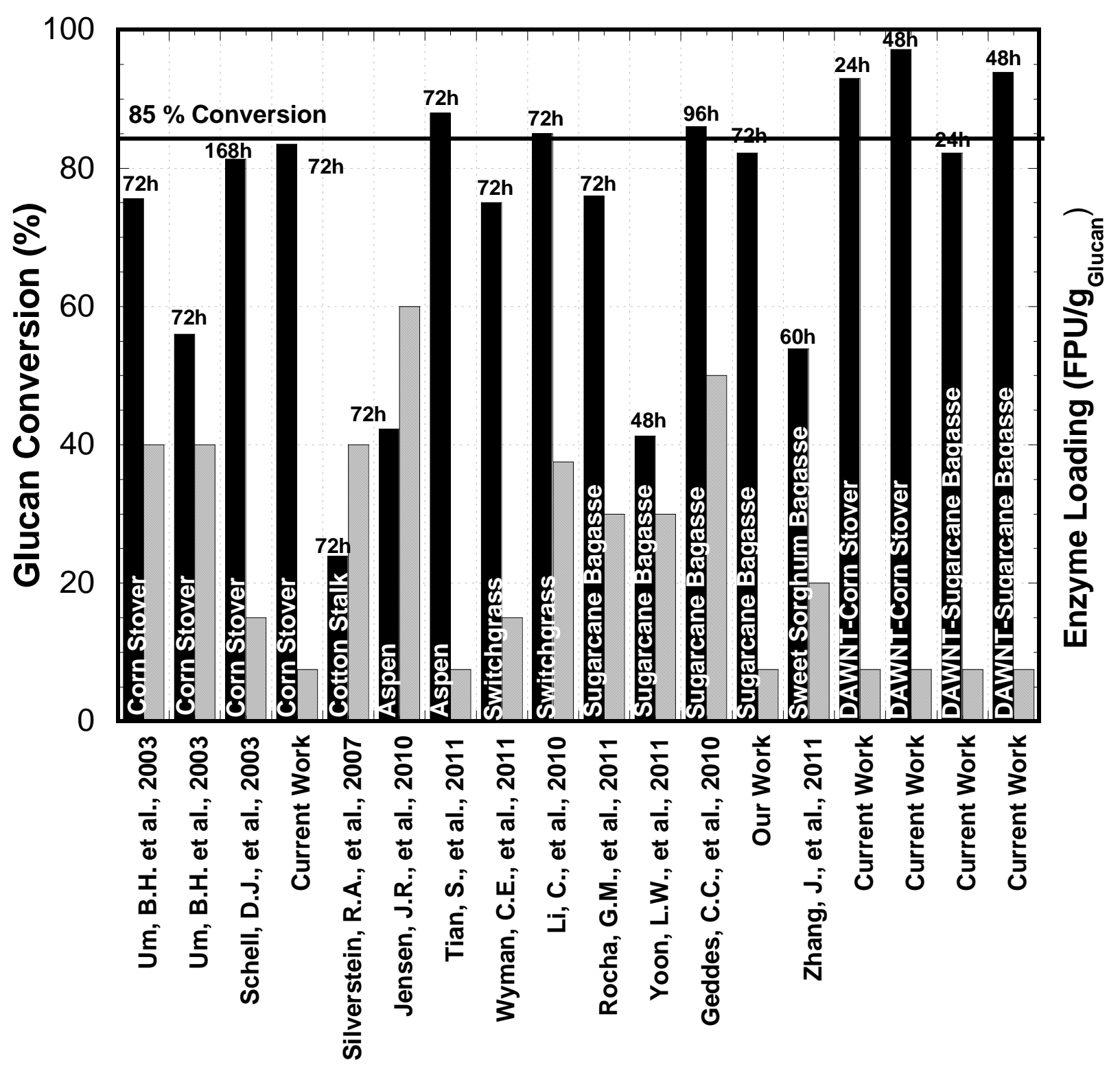

Figure 5 


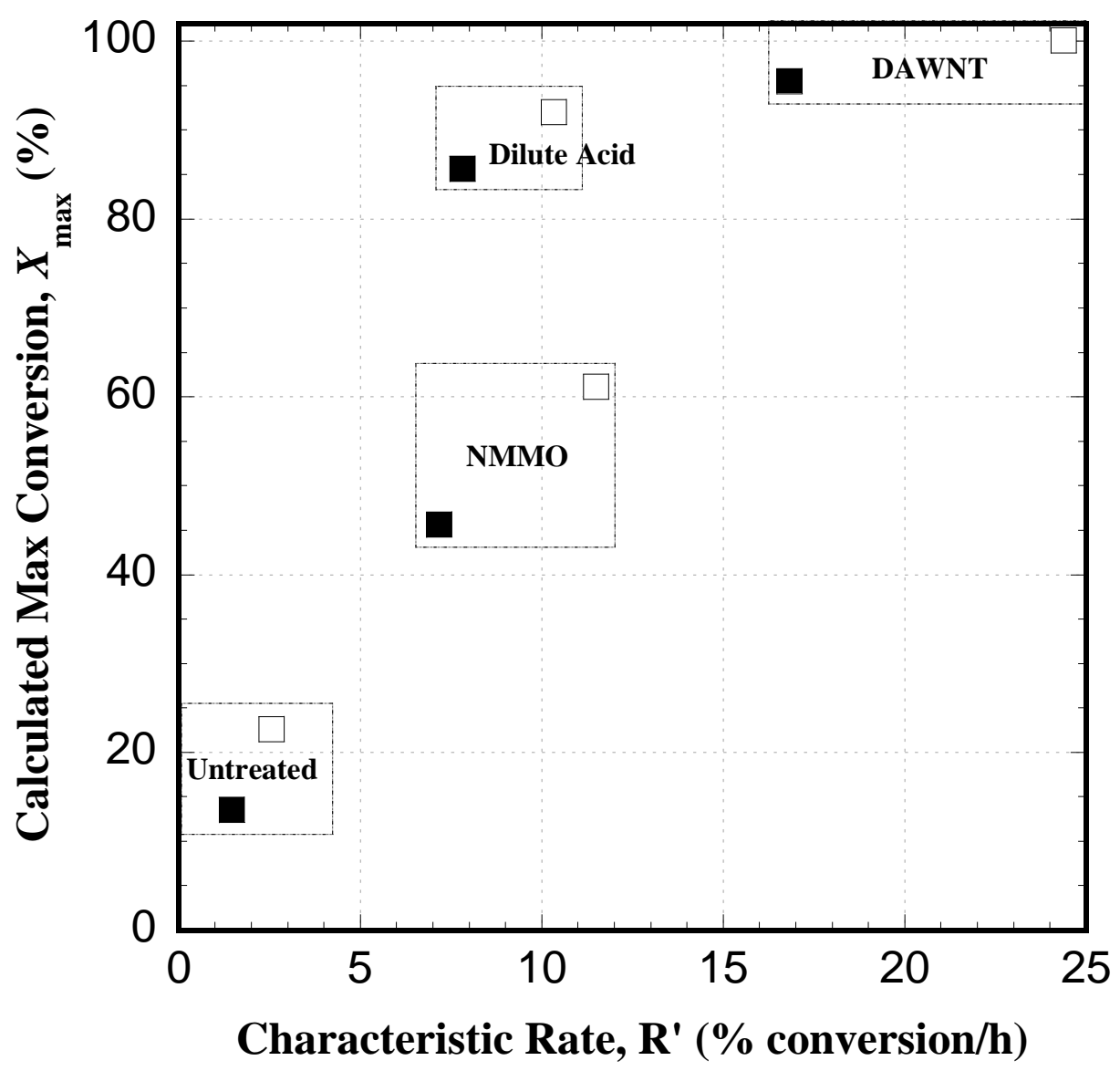

Figure 6 
DAWNT (dilute acid followed by NMMO treatment)

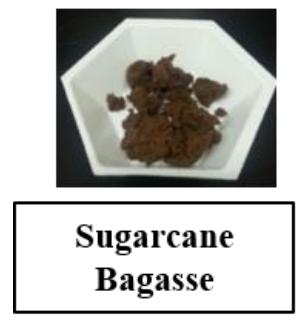

Digestible

Carbohydrate

Fraction

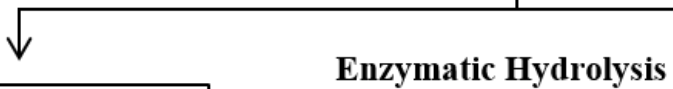

Lignocellulosic Biomass

Dilute Acid Treatment

Dilute Acid Treated

Biomass

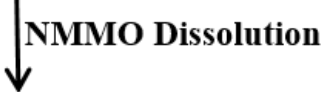

Solubilized

Hemicellulose (Xylose)

Solubilized Cellulose

(Glucose) Regeneration

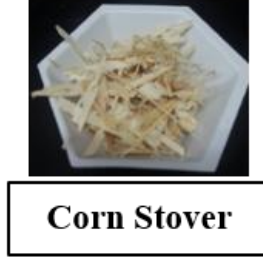

Two stage pretreatment for biomass fractionation and enhanced yields and reaction rates
DAWNT Treated

Biomass Lignin Fraction

Unreacted Solid
Lignin Fraction

\section{$\downarrow$}

Residual Solid

(Lignin) 